\title{
Rancang Bangun Sistem Informasi Customer Relationship Management Terhadap Penilaian Pelanggan Berbasis Web
}

\author{
Andri Cahyo Purnomo ${ }^{1}$, Nur Felia ${ }^{2}$, Halimah febbi budiana ${ }^{3}$ \\ 1,2,3 Program Studi Sistem Informasi Universitas Raharja \\ Email : ${ }^{1}$ andricahyo@raharja.info, ${ }^{* 2}$ nurfelia@ raharja.info, ${ }^{3}$ Halimah.febbi@ raharja.info
}

\begin{abstract}
Abstrak
Permasalahan yang terjadi yaitu sistem CRM (Customer Relationship Management) masih semi komputerisasi yaitu menggunakan Microsoft Excel untuk pengolahan datanya. Sehingga menimbulkan masalah antara lain: pelayanan pelanggan lambat, dan respon perusahaan terhadap pelanggan tidak maksimal. Untuk mengatasi hal tersebut maka dibutuhkan sebuah aplikasi berbasis website agar menyelesaikan masalah yang terjadi saat ini. Dalam perancangan aplikasinya menggunakan analisis SWOT dan diagram UML (Unified Modeling Language), serta menggunakan bahasa pemrograman PHP (Hypertext Preprocessor), Framework Codeigniter, XAMPP. Server database menggunakan MySql dan sublime text 2 sebagai editor teks. Sehingga dengan aplikasi ini penilaian pelanggan menjadi efisien dan optimal.
\end{abstract}

Kata Kunci : Customer Relationship Management (CRM), Penilaian, Pelanggan.

\begin{abstract}
The problem that occurs is that the CRM (Customer Relationship Management) system is still semi-computerized, namely using Microsoft Excel for data processing. Resulting in problems, among others: slow customer service, and the company's response to customers is not optimal. To overcome this, a website-based application is needed to solve the problems that are happening today. In designing the application, it uses SWOT analysis and UML (Unified Modeling Language) diagrams, and uses the PHP (Hypertext Preprocessor) programming language, Codeigniter Framework, XAMPP. The database server uses MySql and Sublime Text 2 as a text editor. So that with this application customer assessment becomes efficient and optimal.
\end{abstract}

Keywords: Customer Relationship Management (CRM), Assessment, Customer.

\section{PENDAHULUAN}

Seiring dengan perkembangan model bisnis dan teknologi, perusahaan juga dituntut untuk meningkatkan kepuasan pelanggan dan menjalin hubungan yang erat dengan pelanggan dalam jangka panjang. tidak hanya mengutamakan penjualan produk tetapi juga mengutamakan kepuasan kepada pelanggan selama pelanggan masih bekerja sama dengan perusahaan dan pelanggan puas dengan produk yang berkualitas dengan produk ekspor yang berkualitas. Sistem yang saat ini digunakan pada perusahaan yang bergerak di bidang distribusi adalah pelanggan yang masih menggunakan sistem semi komputerisasi, sehingga dalam evaluasi pendistribusiannya pelanggan tetap melakukannya melalui email maupun telepon. Sehingga perusahaan tidak memiliki strategi minimal dalam aktivitas yang menangani hubungan antar pelanggan. Hal inilah yang mempersulit perusahaan untuk berinteraksi dengan pelanggan secara personal sehingga perusahaan tidak dapat mengetahui kepuasan pelanggan yang menyebabkan 
perusahaan kesulitan mendapatkan pelanggan baru, karena pelayanan kepada pelanggan di bidang pemesanan belum optimal.

\section{Customer Relationship Management}

Tama yang dikutip wardani (2020:15), menyimpulkan bahwa Customer Relationship Management (CRM) merupakan pendekatan komprehensif yang menggabungkan setiap proses bisnis yang berhubungan langsung dengan konsumen, dalam bentuk penjualan, pemasaran dan layanan pelanggan melalui integrasi filosofi, teknologi, dan proses. ${ }^{[1]}$

\section{Kepuasan Pelanggan}

Alvioletta, dkk (2020:17), menyimpulkan bahwa jika pelanggan merasakan kepuasan terhadap suatu produk maka pelanggan akan bertahan dalam waktu lama menggunakan produk tersebut. begitu pula sebaliknya, kepuasan pelanggan menjadi tolak ukur dalam mencapai kesuksesan yang berdampak pada tingkat penjualan suatu produk. [2]

\section{Kualitas layanan}

Pattaray, dkk (2021:11), menyimpulkan bahwa Kualitas layanan merupakan ukuran keunggulan yang diharapkan dari kualitas layanan yang dikaitkan dengan perkembangan harga atau tingkat perbandingan penghargaan kualitas jasa konsumen dengan kinerja perusahaan yang dipersepsikan oleh konsumen untuk mengendalikan perkembangan harga.[3]

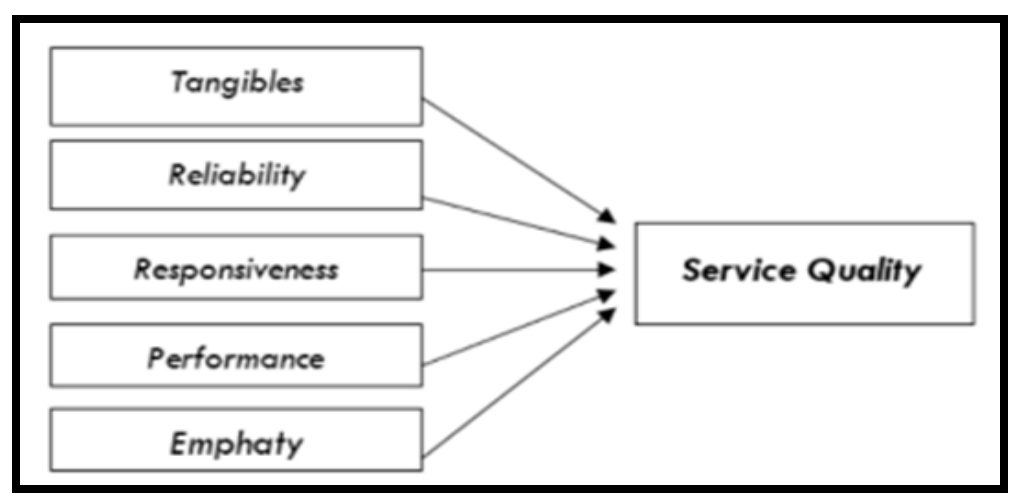

Gambar 1. Faktor-Faktor Kualitas Pelayanan

\section{Analisa SWOT}

Sari dkk (2020:109), Analisis SWOT adalah evalausi menyeluruh atas kekuatan, kelemahan, peluang, dan ancaman yang dimiliki dan dihadapi oleh perusahaan. Jika analisa kekeuatan dan kelemahan adalah analisa terhadap kondisi internal perusahaan, maka peluang dan ancaman merupakan analisis kondisi eksternal perusahaan. [4]

\section{Penelitian Terkait}

Bagian ini akan sedikit menjelaskan tentang penelitian yang telah dilakukan sebelumnya.

Hadi dan aida (2019) ${ }^{[5]}$ dalam penelitiannya Perancangan Sistem Informasi Customer Relationship Management (CRM) Untuk Meningkatkan Loyalitas Dan Pelayanan Customer Berbasis Web Dengan Model Waterfall. Hasil dari penelitian yang dibuat menggunakan model waterfall menghasilkan sistem yang dapat meningkatlan kualitas pelayanan kepada pelanggan yang sangat membantu perusahaan dalam mengetahui keluhan berupa kritik dan saran yang disampaikan customer untuk meningkatkan pelayanan kepada konsumen; Elizabeth dan Riri (2019) $^{[6]}$ dalam penelitiannya Perancangan Sistem Informasi Customer Relationship Management Berbasis Web Untuk Meningkatkan Loyalitas Pelanggan. Hasil dari penelitian yang dibuat menghasilkan sistem yang memudahkan pelanggan dala melihat informasi detail 
layanan laundry, status laundry sehingga dapat menghemat waktu pelanggan, serta mempermudah kinerja petugas dalam pengolahan data dan permintaan pick up; Yuniar dan Handriani (2020) ${ }^{[7]}$ dalam penelitiannya Sistem Customer Relationship Management Untuk Perusahaan Penjualan Alat Komputer Menggunakan Analisis Fishbone. Hasil dari penelitian yang dibuat menghasilkan sistem yang dapat memberikan informasi layanan tentang pesanan penjualan, purna jual, pembaruan data produk, dan informasi piutang pelanggan sehingga dapat menjaga hubungan perusahaan dengan pelanggan dan meningkatkan loyalitas pelanggan kepada perusahaan.

\section{METODE PENELITIAN}

\begin{tabular}{|c|c|c|c|}
\hline Strengths (Kekuatan) & $\begin{array}{c}\text { Weakness } \\
\text { (Kelemahan) }\end{array}$ & $\begin{array}{c}\text { Opportunities } \\
\text { (Peluang) }\end{array}$ & Threats (Ancaman) \\
\hline $\begin{array}{l}\text { 1. Tersedianya fasilitas } \\
\text { pendukung teknologi } \\
\text { informasi, seperti } \\
\text { akses internet } \\
\text { 2. Pelanggan terus } \\
\text { menggunakan produk }\end{array}$ & $\begin{array}{l}\text { 1. Mudahnya terjadinya } \\
\text { human error } \\
\text { 2. Masih belum } \\
\text { tersedianya website } \\
\text { yang menyediakan } \\
\text { customer service } \\
\text { 3. Masih adanya } \\
\text { keterlambatan informasi } \\
\text { mengenai pengiriman } \\
\text { barang }\end{array}$ & $\begin{array}{l}\text { 1. Memudahkan } \\
\text { menemukan } \\
\text { pelanggan dan } \\
\text { memenuhi kebutuban } \\
\text { pelanggan. } \\
\text { 2. Perkembangan } \\
\text { teknologi informasi } \\
\text { terus meningkat. }\end{array}$ & $\begin{array}{c}\text { 1. Kurangnya } \\
\text { keamanan, yang } \\
\text { menyebabkan banyak } \\
\text { data mudah bilang } \\
\text { 2. Semakin banyak } \\
\text { kempetitor yang sudah } \\
\text { menggunakan teknolegi } \\
\text { canggih, termasuk } \\
\text { layanan untuk } \\
\text { kebutuban pelanggan } \\
\text { berbasis website dengan } \\
\text { mudah dan cepat }\end{array}$ \\
\hline
\end{tabular}

Gambar 2. Metode Analisis SWOT

Metode yang digunakan dalam penelitian ini Berdasarkan gambar yang telah diterangkan diatas mengenai analissis SWOT merupakan teknik perancangan strategi yang berguna untuk melihat kondisi perusahaan baik internal maupun eksternal yang nantinya akan digunakan sebagai indikator untuk mengetahui kekuatan, kelemahan, peluang dan ancaman sehingga dapat membantu perusahaan dalam pengambilan keputusan

\section{HASIL DAN PEMBAHASAN}

Class Diagram Sistem

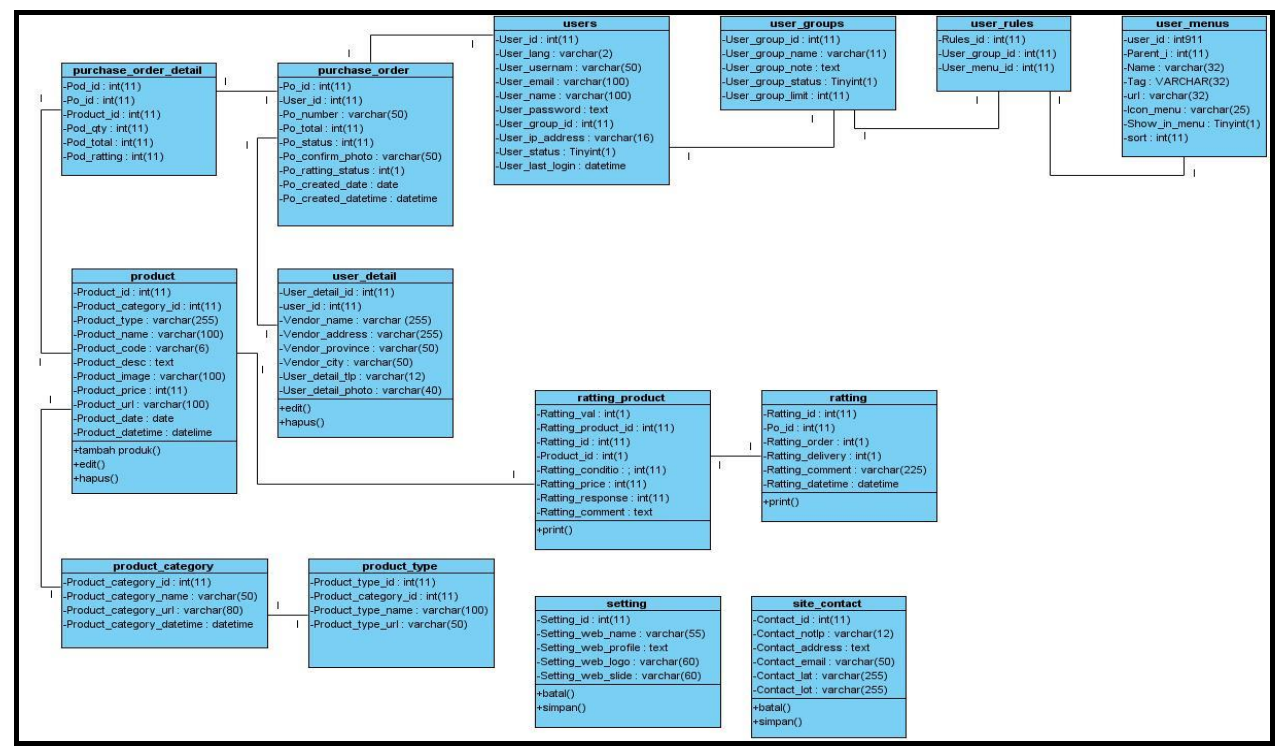

Gambar 3. Class Diagram sistem 
Berdasarkan gambar 3 Class diagram sistem yang dibuat terdapat: 14 class, himpunan dari objek-objek yang berbagi atribut serta operasi yang sama diantaranya t_user, user_group, user_rules, user_menus, user_detail, purchase_order, purchase_order_detail, product, product_category, product_type, ratting_product, ratting, site_setting, contact. Ada 11 association yang mengaitkan satu objek dengan objek lainnya yang memiliki nilai.

\section{Rancangan Program}

\section{Tampilan Menu Registrasi}

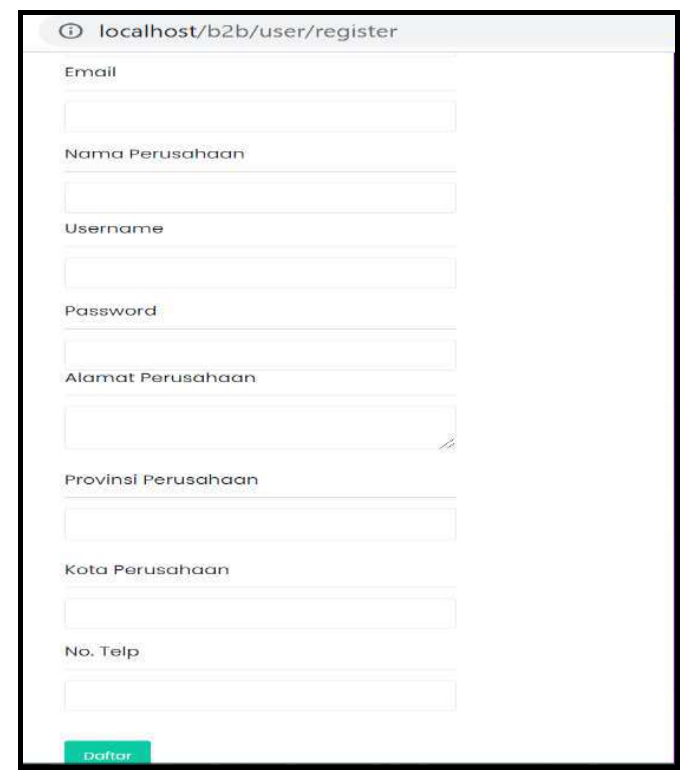

Gambar 4. Tampilan Menu Registrasi

Gambar 4 Menampilkan menu registrasi, berisi registrasi user dan customer dimana mereka harus mengisi data terlebih dahulu untuk dapat mengakses sistem sebelum login

\section{Tampilan Menu Login}

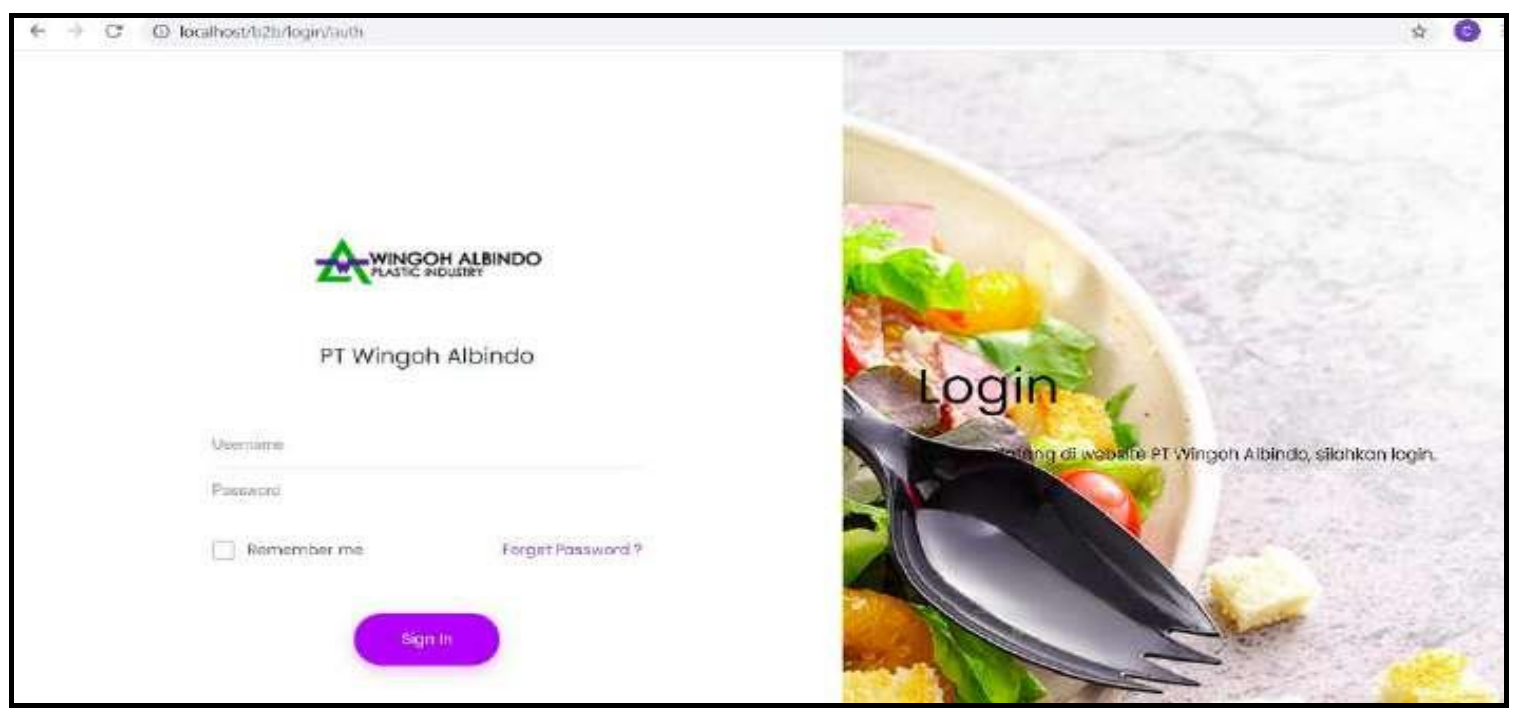

Gambar 5. Tampilan Menu Login 
Gambar 5 menampilkan menu login untuk dapat masuk ke dashboard, yang berisi username dan password dimana pengguna dan pelanggan dapat masuk ke dalam sistem.

\section{Tampilan Menu Halaman Customer}

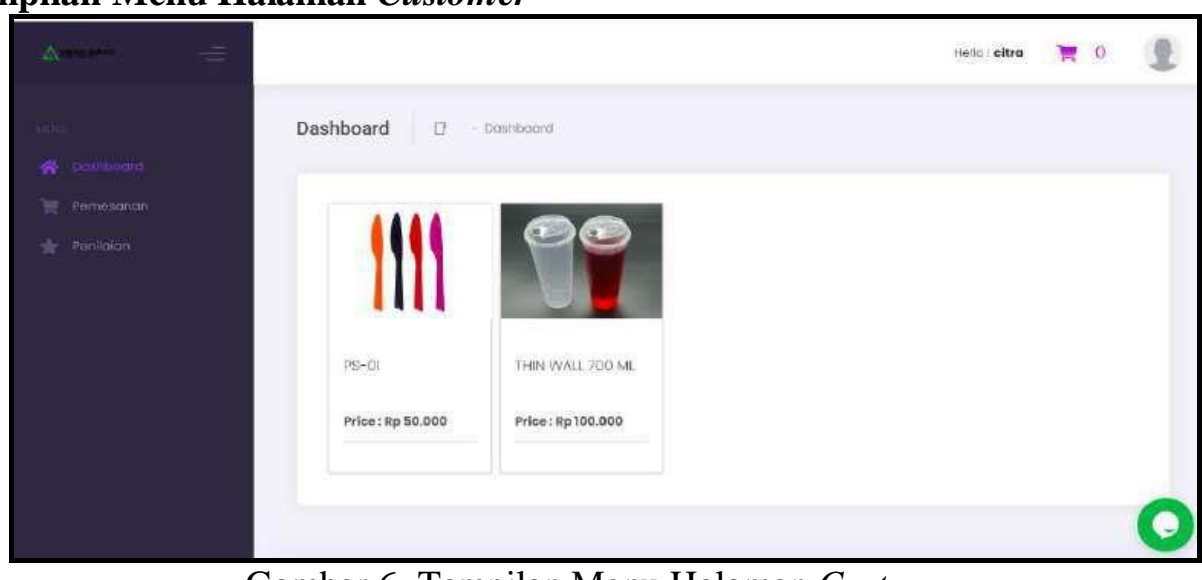

Gambar 6. Tampilan Menu Halaman Customer

Gambar 6 menampilkan gambar produk beserta harganya.

\section{Tampilan Menu Pemesanan}

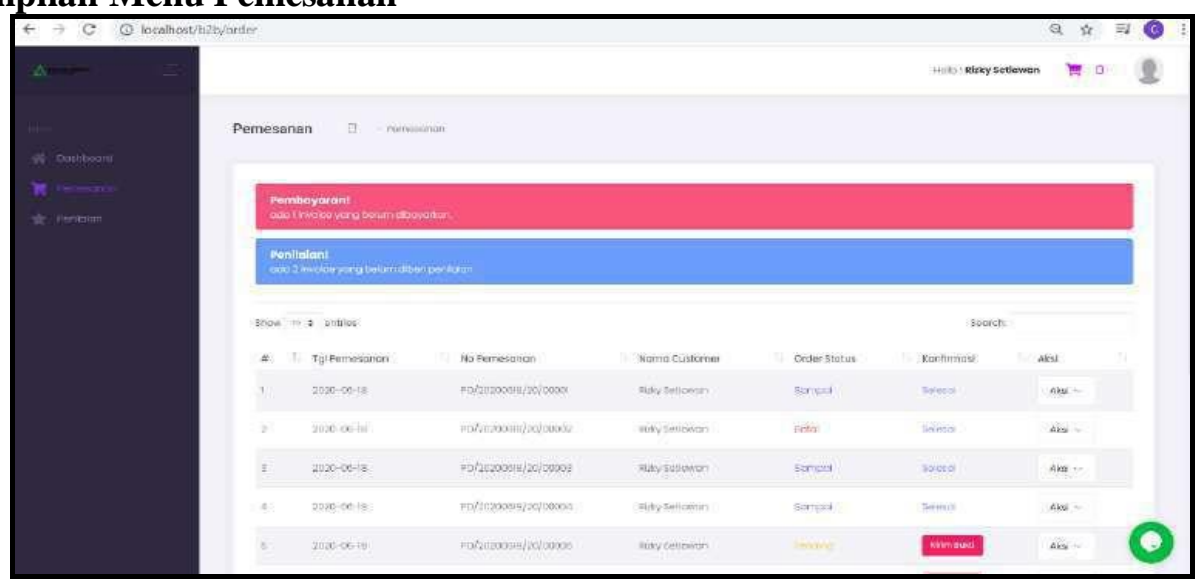

Gambar 7. Menu Pemesanan

Gambar 7 menampilkan status orderan, apakah orderan sudah dikirim atau belum.

\section{Tampilan Menu Penilaian Customer}

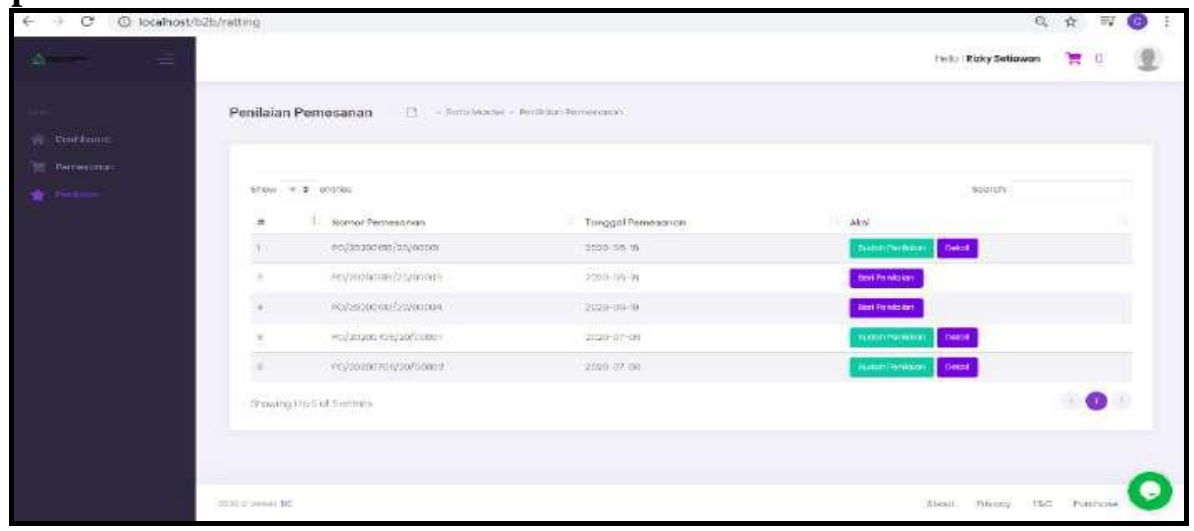

Gambar 8. Tampilan Menu Penilaian Customer 
Gambar 8 menu penilaian customer yang dilakukan setelah customer melakukan pemesanan dan menerima barang.

\section{Tampilan Menu Data Master Produk}

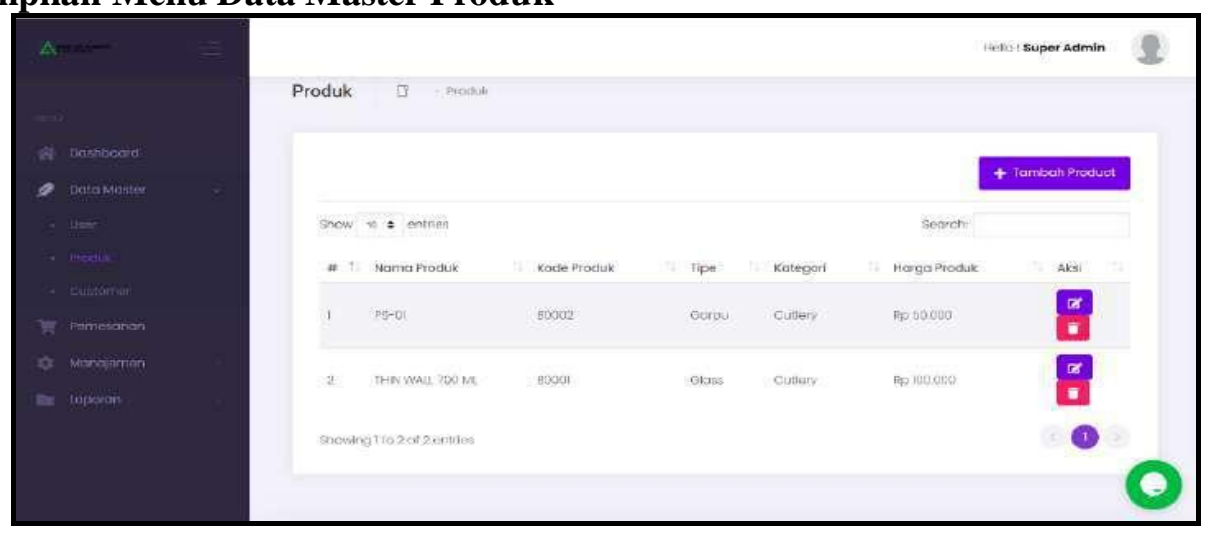

Gambar 9. Tampilan Menu Data Master Produk

Gambar 9 menampilkan menu data master produk dimana hanya admin marketing yang dapat mengakses untuk menambah produk yang akan di masukan kedalam website.

\section{Tampilan Menu Pemesanan}

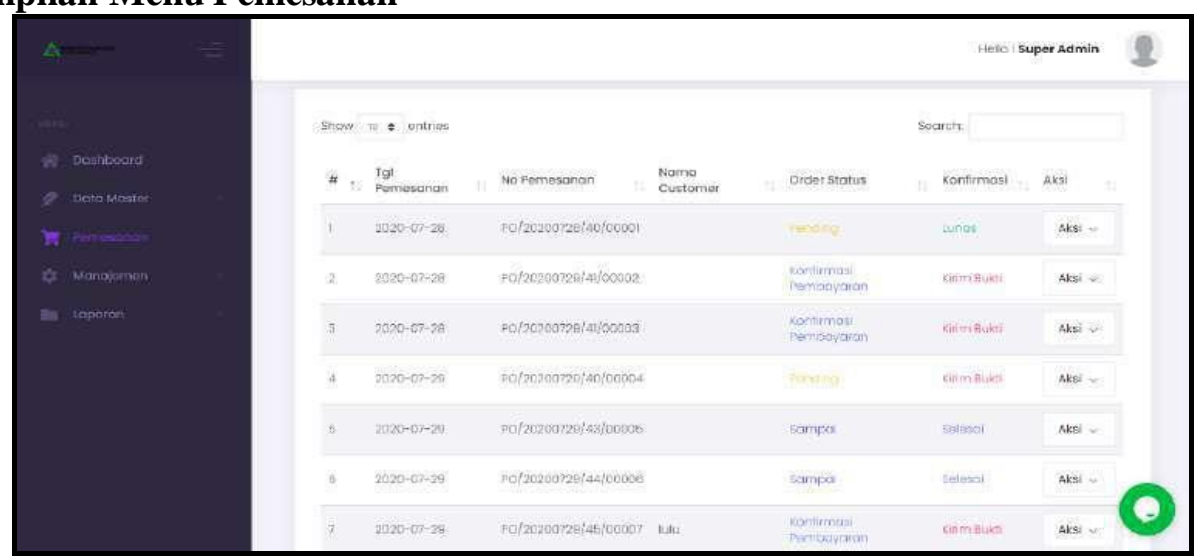

Gambar 10. Tampilan Menu Order Pemesanan

Gambar 10 menampilkan tanggal pemesanan, nomor pemesanan, status orderan, dan status konfirmasi pembayaran.

\section{Tampilan Menu Penilaian Produk}

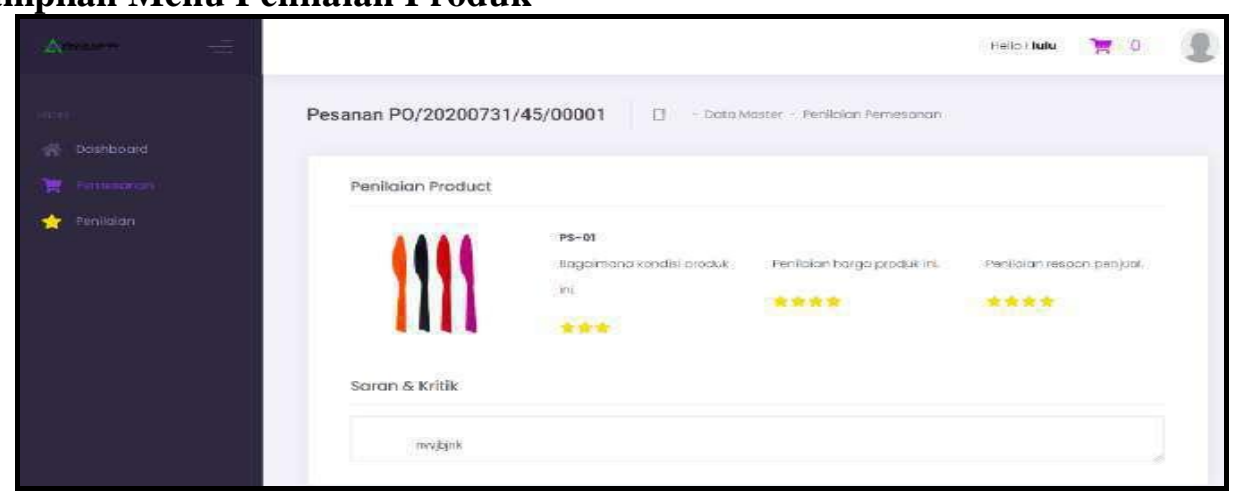

Gambar 11. Tampilan Menu Penilaian Produk 
Gambar 11 menampilkan menu penilaian terhadap produk yang telah dibeli dan diterima oleh customer.

\section{KESIMPULAN}

Kesimpulan dari hasil penelitian adalah sebagai berikut: Proses sistem informasi customer relationship management yang sedang berjalan saat ini masih semi komputerisasi yaitu melalui media email, telepon atau whatsapp. Dalam rangka melakukan transaksi pemesanan barang hingga proses penilaian yang diberikan oleh pelanggan, sehingga banyak pelanggan yang merasa kecewa. Pembuatan sistem berbasis website baru ini telah diuji menggunakan Blackbox Testing dan mendapatkan hasil yang valid. Sistem informasi pada customer relationship management yang dibuat ini dapat menyelesaikan permasalahan yang ada karena dapat memudahkan admin dalam mengelola data pesanan pelanggan, penilaian pelanggan, laporan penjualan hingga laporan penilaian pelanggan.

\section{SARAN}

Disarankan agar Sistem Informasi Customer Relationship Management terhadap Penilaian pelanggan berbasis Web yang telah dibuat ini dapat terus dikembangkan dan ditingkatkan lagi performanya agar sistem informasi ini bernilai dan berdayaguna.

\section{DAFTAR PUSTAKA}

[1] Wardani, N, W. 2020.penerapan Data Mining Dalam Analytic CRM. Medan : Yayasan Kita Menulis

[2] Alvioletta, Velariza., Muhammad Yusril helmi Setyawan., dan M. Harry K Saputra. 2020. Penerapan Metode Analitycal Hierarchy Process (AHP) Pada Penilaian Kepuasan Pelanggan Berdasarkan Pelayanan Divisi (Studi Kasus: CV Tirta encana). Bandung : Kreatif Industri Nusantara.

[3] Pattaray,A., dkk. 2021. KOnsep Pelayanan Bagi Wisatawan Penyandang Disabilitas. Batu : Literasi Nusantara

[4] Sari, A, P., dkk. 2020. Kewirausahaan dan Bisnis Online. Medan : Yayasan Kita Menulis

[5] Hadi, Z., \& Marlia, A,E. 2019. Perancangan Sistem Informasi Customer Relationship Management (CRM) Untuk Meningkatkan Loyalitas Dan Pelayanan Customer Berbasis Web Dengan Model Waterfall. Jurnal Teknologi Sistem Informasi Dan Aplikasi, 2(2), 66-72

[6] Elizabeth, E., \& Setianingsih, R. 2019. Perancangan Sistem Informasi Customer Relationship Management Berbasis Web Untuk Meningkatkan Loyalitas Pelanggan. Jurnal Informatika dan Komputasi (JIK), 13(1), 9-15

[7] Yuniar, N. F., \& Handriani, I. 2020. Sistem Customer Relationship Management untuk Perusahaan Penjualan Alat Komputer Menggunakan Analisis Fishbone. Teknika, 9(2), 129-137 